\title{
Three-dimensional anatomy of the ostrich (Struthio camelus) knee joint
}

Kyle P Chadwick, Sophie Regnault, Vivian Allen, John R. Hutchinson

The three-dimensional anatomy of the ostrich (Struthio camelus) knee (femorotibial, femorofibular, and femoropatellar) joint has scarcely been studied, and could elucidate certain mechanobiological properties of sesamoid bones. The adult ostrich is unique in that it has double patellae, while another similar ratite bird, the emu, has none. Understanding why these patellae form and what purpose they may serve is dually important for future studies on ratites as well as understanding mechanobiological characteristics of sesamoid bone development. For this purpose, we present a three-dimensional anatomical study of the ostrich knee joint, detailing osteology, ligaments and menisci, and myology. We have identified seven muscles which connect to the two patellae and compare our findings to past descriptions. These descriptions can be used to further study the biomechanical loading and implications of the double patella in the ostrich. 
1 Three-dimensional anatomy of the ostrich (Struthio camelus) knee joint

2 Kyle P. Chadwick, Sophie Regnault, Vivian Allen, John R. Hutchinson

3 Structure \& Motion Lab, Department of Comparative Biomedical Sciences, The Royal Veterinary

4 College, Hawkshead Lane, Hatfield AL9 7TA, United Kingdom

5 Contact: kchadwick@rvc.ac.uk 


\section{Introduction}

Ostriches (Struthio camelus) are well known for their exceptional bipedal running abilities (e.g., Alexander et al. 1979). Their muscular, three-dimensionally mobile legs (Rubenson et al., 2007) are attractive subjects for studies of mechanical forces in the knee because they are able to accommodate large dynamic loads (Rubenson et al., 2010; Hutchinson et al., 2014). This large dynamic loading of the pelvic limbs in ostriches raise questions of how much support is active (i.e. muscular) vs. passive (skeletal, ligamentous, etc.) and the relative roles of the many structures in the knee region.

The knee joint sesamoid bones (kneecaps or patellae) in ostriches are of particular interest, because - unusually for birds and indeed all other animals - they are present as double (proximal and distal) rather than single bones. This has been recognized for at least a century and a half (Macalister, 1864; Haughton, 1864), however, until recently the double patellar sesamoids of ostriches have been overlooked in a comparative context. Regnault et al. (2014) showed that ostriches are unusual among ratite (Palaeognathae) birds in having these two patellae-emus and other ratites (e.g. cassowaries, extinct moa) appear to have lost the patella completely, whereas kiwis and tinamous have retained a plesiomorphically small patella. The condition in other species is uncertain, and although Stannius (1850) and de Vriese (1909) hint of a double patella in Rhea, evidence so far indicates that the double patella evolved only once: within the lineage leading to Struthio.

All bones develop under a combination of genetic and epigenetic (mechanical) inputs, but sesamoid bones including the patella appear to be particularly dependent on early biomechanical influences (Sarin et al., 1999), with poor formation or complete developmental failure in embryonic immobilisation studies (Mikic et al., 2000; Osborne et al., 2002; Kim et al., 2009). Although the relative importance of biomechanical stimulation seems to vary amongst species and sesamoids (Vickaryous and Olson, 2007, Kim et al., 2009), it is clear that some aspect of normal embryonic movement is vital for sesamoid formation. Through the use of 3D models and finite element analysis, previous researchers have found that sesamoid ossification centres occur in regions of high tissue stress (Roddy, 2011). Moreover, it seems that the type of stress is key; high octahedral shear (i.e., pure shear) stresses appear to promote sesamoid ossification whereas hydrostatic (i.e., pure normal) stresses inhibit it (Sarin \& Carter, 2000; Giori, 1993).

Multiple studies of real tissue in and ex vivo corroborate these ideas, and have found regions of fibrocartilage and bone proliferation corresponding with areas of compressional loading (Scapinelli \& Little, 1970; Benjamin \& Ralphs, 1997; Vogel \& Peters, 2005). Potential mechanosensitive genes involved in the regulation of embryonic ossification have been identified (Nowlan et al., 2008), though investigation of the role of genetics in sesamoid formation is complex and ongoing. Most researchers conclude that both mechanical and genetic factors interact and play complementary parts in creating sesamoid bones. In studying long bones, Carter et al. (1998) hypothesised that the relative rate of perichondral vs. endochondral ossification (controlled by genetics) in turn creates a biomechanical environment favourable (if the two occur simultaneously) or unfavourable (if perichondral precedes endochondral ossification) to the formation of secondary centres. Carter (1987) postulated that variations in genotype, favoured over time by natural selection, work in concert with mechanical stimuli through ontogeny to create mechanically efficient designs in vertebrate skeletons.

The aforementioned studies provide plausible explanations for the large variation of sesamoids across vertebrate taxa, even amongst those with grossly similar mechanical loading (e.g. birds; Regnault et al., 2014). However, more case studies are needed about the biomechanical function(s) that sesamoids perform in an individual at any one time, how those roles are moulded during ontogeny, and how the form and function of sesamoids evolve. In particular, it is not yet clear how much the sensitivity of sesamoids to their mechanical environment varies-are some, such as the patella, more phenotypically plastic in some taxa (e.g. birds) than others (e.g. mammals) (Barnett \& Lewis, 1958)? If so, has any differential 
58

59

60

61

62

63

64

65

66

67

68

69

70

71

72

73

74

plasticity of sesamoid development played an important role in evolution, such as undergoing genetic assimilation (Sarin et al., 1999), or indicating key changes in locomotor function that correspond to altered loads on sesamoids (Hutchinson, 2002)?

We are interested in questions such as, within what tendons are the patellae developed and how are they loaded by the surrounding tissue? We aim to investigate these questions using a three-dimensional (3D) model of knee joint morphology. To do this, we scanned and digitally segmented the ostrich knee structures (muscles, ligaments, and bones) into discrete elements, allowing connecting tissues and muscles to be described and measured. We present an anatomical description of the morphology of the knee joint of ostriches, with a focus on features that are most relevant to the mechanics of the two patellae. Anatomy of the knee region has been characterized in numerous birds (Haines, 1942; Cracraft, 1971; Abourachid, 1991; Fuss \& Gasser, 1992), and several studies contain descriptions of knee tissues in ostriches (Macalister, 1864; Haughton, 1864; De Vriese, 1909; Fowler, 1991, Bezuidenhout, 1999; Gangl, 2004; Wagner, 2004; Zinoviev, 2006; Smith, 2006). None of these studies focus directly on the two patellae and their interaction with surrounding tissues. The anatomy is not simple and is best understood with a full three-dimensional perspective; therefore we present an interactive 3D representation of a representative knee in a mature ostrich.

\section{Materials and methods}

Our 3D model is based on the right leg of a skeletally mature adult (unknown age) male ostrich, body mass $71.3 \mathrm{~kg}$. It was imaged with digital radiography (Figure 1; Philips MX 8000 IDT 16 scanner, 16 bit images, $\sim 428 \times 352 \mathrm{~mm}$ images at 10 pixels $\mathrm{mm}^{-1}$ resolution, varying $\mathrm{kV}$ and mAs), computed tomography (CT; Philips MX 8000 IDT 16 scanner, 120 kV, 100 mAs, $0.8 \mathrm{~mm}$ slice thickness), and magnetic resonance imaging (MRI; Philips Medical Systems Intera scanner, TR: $3596 \mathrm{~ms}$, TE: $120 \mathrm{~ms}$, $\alpha: 90^{\circ}, 3 \mathrm{~mm}$ slice thickness). Following this the leg was dissected to qualitatively study the anatomy, and these observations validated through dissections of three other individuals (adults of unknown age, 65.3 and $130 \mathrm{~kg}$ body mass at death), CT imaging of six individuals (settings similar to those above), comparative studies of museum specimens (Table 1 and 15 others from various collections), and consultation of the relevant literature (cited above), to ensure that our observations on this individual were as representative as possible. All specimens were acquired from local farms after being euthanized for health reasons unrelated to this study.

To construct the model, we segmented the resulting DICOM images from CT and MRI for our representative ostrich specimen (and select comparative specimens) in Mimics (Materialise Inc., Leuven, Belgium) software. Bones were segmented from CT images and muscles were segmented from MRI images. The segmentations were individually and semi-automatically rendered into 3D objects. The 3D images of the bones were co-registered with the muscle MRI files and manually aligned to fit the limb posture from the MRI scan. This allowed 3D objects representing all relevant bones and muscles to fit together into a single model.

\section{Results}

The bones, muscles, ligaments, and menisci forming the 3D model created in this study can be viewed as a 3D PDF, hosted here http://dx.doi.org/10.6084/m9.figshare.1252187, or as individual STL files, hosted here http://dx.doi.org/10.6084/m9.figshare.1252166.

Osteology

The knee joint of an adult ostrich has five component bones: the distal femur, the proximal tibia and fibula, and the proximal and distal patella (Figure $2 \mathrm{~b}$ ). The femur has asymmetric condyles, the lateral being appreciably larger than the medial. While we observed 
104 general asymmetry in other ratites, the differential size between lateral and medial condyle 105 appears to be greatest in the ostrich. There is also a large lateral femoral epicondyle lateral to 106 the lateral femoral condyle, forming a fibular trochlea. The tibiotarsus has lateral and cranial tibial crests extending from those two aspects of the proximal tibia.

The proximal patella lies high on the lateral femoral condyle, dipping slightly into the large sulcus in the position the specimen was scanned in (similar to that in three other specimens scanned). The proximal patella therefore topologically corresponds to the single patella of other birds, which occupies a position within or slightly above the sulcus (Shufeldt, 1884; Haines, 1942; Cracraft, 1971), and its flattened morphology likewise is similar.

The distal patella, which has only been briefly mentioned in literature (Macalister, 1964; De Vriese, 1909; Walker, 1890; Bezuidenhout, 1999; Gangl, 2004; Wagner, 2004), is 75.7mm long in our subject (ossified portion; Table 1) and sits in front of the lateral femoral condyle. There was considerable variability in the distal patella lengths we observed in our dissected and museum specimens, however the length does roughly correlate with femur length (Table 1), which suggests a correlation with age. The distal patella extends down to just above the tip of the tibial crest, where it is connected by a short band of connective tissue $(\sim 3 \mathrm{~mm})$, apparently corresponding to a distal remnant of the patellar tendon. This distal-most sesamoid, much like the patella observed in some diving species (Shufeldt, 1883, 1884; Walker, 1890), appears like a proximal extension of the tibial crest, observed in other species such as Colymbus glacialis (Walker, 1890; Vickaryous \& Olson, 2007). Both patellae are enveloped by a thick, fibrous facial sheet to which many tendons contribute. While neither patella articulates directly with any other bone in the knee (through an articular cartilage interface), the layer of fibrous tissue between the femur and proximal patella is thin and may allow transmission of contact forces in some poses or loading regimes.

128

129

130

131

132

133

134

135

136

137

138

139

140

141

142

143

144

145

146

147

148

149

150

151

152

153

154

155

\section{Ligaments and Menisci}

There are four primary ligaments which provide stability and alignment in the knee joint of ostriches, as in many other tetrapods (Figure 2a; Fuss, 1989, 1991, 1996). A wide, flat collateral ligament spans the femorotibial joint space on either side, laterally and medially. The medial collateral ligament (MedCL) connects the medial femoral condyle to the tibiotarsus. It originates within a small fossa on the distal medial side of the medial femoral condyle and inserts distally to the tibial plateau on the medial edge of the proximal tibia. The lateral collateral ligament (LatCL) originates on the distal part of the lateral femoral epicondyle, and inserts onto the fibula, on the posterior-distal corner of the lateral side of the bulbous epiphysis, as well as the lateral meniscus, on the lateral side of the large, pointed cranial extension of the meniscus. There is additionally a larger lateral collateral ligament (LatCL_2) which originates at the very top of the lateral femoral condyle, inserts on the shaft of the fibula, and also connects cranially to the meniscus. The cranial cruciate ligament (CranCL) is round in cross-section, originates caudally (in the popliteal fossa) between the femoral condyles and inserts cranially on the tibial plateau (Figure 3a). The caudal cruciate ligament (CaudCL) is thicker and flatter. It originates from a small impression on the medial side of the lateral femoral condyle, crosses over the top of the CranCL, and inserts on the caudomedial corner of the tibial plateau (Figure 3a). We found slight differences in size and shape of attachments, particularly on the tibial head, from previous descriptions (Fuss \& Gasser, 1992), however the general location agreed (Figure 3b).

The medial meniscus sits between the medial femoral condyle and the tibial plateau. It is circular, thickest on its outermost aspect and thinner towards the incomplete centre, so that it forms a triangular wedge in cross section. Cranially, the medial meniscus connects to the lateral meniscus. The lateral meniscus is smaller than the medial meniscus and is longer (craniocaudally) than it is wide (mediolaterally). It sits primarily in the gap between the tibiotarsus and the fibula and extends cranially up the lateral femoral condyle. The femoral meniscal ligament attachments match well with Fuss and Gasser's (1992) descriptions, however the tibial attachments differ in size and two meniscal attachments on the fibula were found, which were not previously noted (Figure 3b). 
156

157

158

159

160

161

162

163

164

165

166

167

168

169

170

171

172

173

174

175

176

177

178

179

180

181

182

183

184

185

186

187

188

189

190

191

192

193

194

195

196

197

198

199

200

201

202

\section{Discussion} side of the tibial head. The origin of the FMTLD is al the entire later f fomol inserts onto the deep tendofascial sheet above the lateral femoral condyle. The FMTLP origin occurs laterally on the trochanteric crest of the femur, and laterally on the proximal femoral shaft (Gangl et al., 2004), and inserts into the deep tendofascial sheet near the proximal patella. The FMTIM arises from the trochanteric crest and proximal three-quarters of the cranial femoral shaft (Gangl et al., 2004), and inserts on the deep tendofascial sheet, near the proximal patella and directly above the medial femoral condyle. A third femorotibial muscle, M. femorotibialis medialis, crosses the knee joint from the medial femoral shaft to the medial surface of the proximal tibia but does not interact with the patellar tissues and thus is not further described here (but see Zinoviev, 2006 for an accurate account; and Hutchinson et al., 2014 for some explanation of confusion surrounding these femorotibial muscles' identities in other literature).

The thin, round tendon of the AMB1, which originates from the pectineal (preacetabular) process of the pubis, runs through the tendofascial sheet and directly behind the distal patella in a distolateral direction, toward its fusion with the tendinous origin of M. flexor perforates digiti III, distal to the fibular head (Gangl et al., 2004). We observed that there were no direct tissue connections between the AMB1 tendon and the patellae. The tendon was free to slip and move independently within the tendofascial sheet, behind the distal patella, unlike in many other (neognath) birds in which the AMB1 tendon perforates or grooves the front of the patella (e.g. Shufeldt, 1884). However, we describe it here as it does run close to the patellae. The second head of M. ambiens, which is unique to ostriches, originates dorsal to the other from the cranioventral iliac rim and inserts on the medial surface of the proximal tibia (Hutchinson et al., 2014). However, it does not come near the patellae and so we do not further describe it.

The lower limb muscles of ostriches also have associations with the patella. The GL originates on the proximolateral side of the distal patella and superficial tendofascial sheet, joining with the GM and GIM into a single gastrocnemius end-tendon distally, and inserting onto the tarsometatarsus after wrapping around the intertarsal joint. The FL attaches to the distolateral side of the distal patella and splits into two tendons of insertion proximal to the intertarsal joint, Tendo lateralis and Tendo caudalis. Tendo lateralis inserts on the tendon of the M. flexor perforates digiti III, distal to the intertarsal joint, and the Tendo caudalis inserts on the lateral tibial condyle (Gangl et al., 2004). The GM takes its origin from the superficial tendofascial sheet and the medial side of the distal patella, and joins the gastrocnemius endtendon before the intertarsal joint. Other lower limb muscles such as $\mathrm{M}$. tibialis cranialis, $\mathrm{M}$. popliteus and the many digital flexors do not originate near the patellae and are well described in the literature (Gangl et al., 2004; Zinoviev, 2006), so we do not discuss them here. 
We scanned, modelled, and dissected an ostrich knee and found previously undescribed or unclear morphology which may be crucial in ostrich knee function. Literature and other specimens bolstered our findings. From the detailed, three-dimensional anatomical data that we collected, we are able to confidently describe the functional attachments of muscles to the tendofascial sheets containing the two patellae, suggest mechanical implications of these attachments in a dynamic limb, and compare our findings to previous anatomical descriptions.

\section{Functional Attachments}

To understand the loading across the knee joint of ostriches, identification and description of the tissues which directly interact with the two sesamoid bones is essential (Figures 2-4). The two sesamoids are embedded in sheets of tendofascial tissue that bond together at the proximal edge of the distal patella. The sheets are the origins and insertions of various leg muscles. The proximal sesamoid constitutes the insertion of the FMTIM tendon proximal-medially and the FMTLP tendon proximal-laterally. Distally, the sheath attaches to the distal sesamoid. The distal sesamoid forms the insertion for the FMTLD tendon proximal-laterally and the IC tendon proximally. The distal sesamoid also is part of the muscle origins of the GL proximal-laterally, the FL distal-laterally, and the GM medially.

Based on our anatomical observations, we hypothesize that all seven of the muscles attached to the patellae would induce a compressive (into the joint) stress on the patellae. The GL, FL, and GM would also induce a tensile force component in the distal direction while the IC, FTIM, FMTLP, and FMTLD would exert a tensile force component in the proximal direction. This could create areas of large compressive and shear loading near the joint as the tissues wrap around the femoral condyles. In addition to the proximal-distal loading, additional mediolateral loads may occur as a result of the tissues wrapping around the distal femur where there is a complex surface between the large lateral condyle and deep sulcus. This variegated surface may induce higher stress concentrations in areas where the surface geometry is most irregular.

\section{Patellar anatomy, connections, and evolution}

The first two (in 1894) mentions of ostriches having a second patella described it not as a true patella, but as an "ossified ligamentum patellae" (Macalister, 1964; Houghton, 1864). Since then there have been several other descriptions. Walker (1890) mentioned a small double patella in ostrich while De Vriese (1909) described the patellae as large, consisting of two successive parts which connected to the tibia by a short ligament. Fowler (1991) claimed that ostriches only had a single ossified bone in the tendon which inserted onto the cnemial crest. We found this to be untrue of our adult subjects. In a juvenile ostrich hindlimb we observed joints which were not fully ossified and no patellae were detected, but it is still unclear when in ontogeny each patella ossifies.

In more modern literature, there have been two primary papers providing thorough descriptions of the patellae and related ostrich knee anatomy (Bezuidenhout, 1999; Gangl et al., 2004). Bezuidenhout (1999) describes a primary patella with medial and lateral articular surfaces, and a "second patella" distal to the patella. The "second patella" is described as a long bony column extending from the medial bottom edge of the patella to the tibial crest. This account was also the first to detail muscle attachments to the two patellae. Muscles described in association with the patellae were the M. femorotibialis medius (inserts laterally on the patella), the M. femorotibialis accessorius (inserts proximally on the patella), the M. femorotibialis internus (inserts medially on the patella), and the M. gastrocnemius (one of four heads originates from the patella). We consider the three M. femorotibialis to be what we describe as FMTLP and FMTIM (two muscle bellies, vide Zinoviev, 2006; Hutchinson et al. 2014). Gangl et al. (2004) first described what we consider another very important aspect of the double patellae, which is the tendofascial sheet in which they are embedded, connecting multiple muscles and inserting on the Crista cnemialis cranialis. The authors also detailed additional muscles which surround and attach to this tendofascial sheet. The muscles which Gangl et al. (2004) described as inserting onto the tendofascial sheet are the M. iliotibialis cranialis and the M. femorotibialis accessorius - 
255

256

257

258

259

260

261

262

263

264

265

266

267

268

269

270

271

272

273

274

275

276

277

278

279

280

281

282

283

284

285

286

287

288

289

290

291

292

293

294

295

296

297

298

caput mediale (what we describe as FMTIM). The tendon of the M. ambiens (here AMB1) was described as running medially to the proximal patella and caudally to the distial patella through the tendofascial sheet of the knee within its own channel. The M. fibularis longus and the M. gastrocnemius pars medialis were both described as having their origins on the distal patella.

Additional modern studies have also shed light on the patellae through both osteological (Wagner, 2004) and myological (Zinoviev, 2006; Smith, 2006) descriptions. Wagner (2004) added a description of the occurrence and shape of the proximal and distal patella of ostriches at various ages, as well as describing the fascia formed by the ends of multiple tendons which the two patellae are embedded. Zinoviev (2006) described the proximal patella as being embedded within the distal extension of the tendon of the $M$. femorotibialis medius pars distalis (what we describe as FMTIM), whereas Smith et al. (2006) described the patella to be within the flat tendon of insertion of the M. femorotibialis medius, externus, and accessorius (what we describe as FMTLP, FMTLD, and FMTIM, respectively).

The tibial crest (specifically, the cranial crest or crista cnemialis cranialis; see Regnault et al., 2014 for more discussion) in birds has been termed a traction epiphysis, or a projection from the end of a bone shaft with a separate centre of ossification to which a tendon inserts (Barnet \& Lewis, 1958; Parsons, 1904; Vickaryous \& Olson, 2007). Traction epiphyses derive, in an evolutionary sense, from sesamoid bones that have fused to the main bone of tendon/ligament insertion. The concurrent existence of a distinct patella and tibial crest does not falsify the hypothesis that the tibial crest is a traction epiphysis in birds, because the patella could be independent from whatever ancestral sesamoid fused with the tibia to form a traction epiphysis (Hutchinson, 2002). However, to our knowledge the ostrich is the only case among birds of a tibial crest and two patellae appearing concurrently (Barnet \& Lewis, 1958). The most plausible hypothesis is that the distal patella in ostriches is a neomorphic ossification unique to that lineage, rather than an atavistic or plesiomorphic case of a lack of fusion of the traction epiphysis, because the evolutionary sequence of traits in birds is (1) appearance of a cranial cnemial crest in stem (ornithothoracine) birds (Hutchinson, 2002), (2) evolution of a patellar sesamoid in ornithurine birds (Regnault et al., 2014), and (3) origin of a second (distal) patella in ostriches (this study).

However, some birds have a proximally elongate tibial crest that has been proposed to be a patella fused to the proximal tibia (Shufeldt, 1883, 1884; Walker, 1890). The extreme proximity of the distal patella to the tibial crest in ostriches, while autapomorphic, presents an example of an intermediate condition between the ancestral lack of ossification in the distal patellar tendon and the derived state of a proximally extended tibial crest. Such evolutionary trajectories, however, have barely been studied in the lineages in which they may have occurred. Our study shows the need for careful re-examinations, using modern techniques such as 3D imaging, of phylogenetic patterns in the knee joint morphology of birds.

\section{Conclusion}

We have identified and described the tissues surrounding the knee joint in the ostrich and compared our findings to the previous literature. We have also speculated on the mechanics and functions of the anatomical features which directly interact with the patellae. It is still not clear why the double patellae develop in the ostrich, and if particular mechanical factors play a primary role in determining their shape and location. In future work, we intend to address these questions through modelling methods such as finite element analysis.

\section{Acknowledgments}

We thank Richard Lam and Renate Weller for their assistance with all of the scans. We also thank Jeff Rankin and Luis Lamas for sharing their expertise in ratite anatomy. Additionally, 
302 Joanne Cooper, Judith White and Hein Van Grouw at the NHM were very helpful in assisting our 303 accessing of specimens, and Charlotte Brassey for providing access to CT scans of a southern 304 cassowary and rhea. We thank the editor Laura Wilson and one anonymous reviewer in addition 305 to reviewer James Neenan for their helpful critiques of the original manuscript. 


\section{PeerJ Reviewing Manuscript}

306

307 Abourachid A. 1991. Myologie du membre pelvien du dindon domestique Meleagris gallopavo.

308 Anatomia, Histologia, Embryologia 20(1):75-94.

309 Alexander R, Maloiy GMO, Njau R, \& Jayes AS. 1979. Mechanics of running of the ostrich

310 (Struthio camelus). Journal of Zoology 187(2):169-178.

311 Barnett, $\mathrm{CH}$, \& Lewis, OJ. 1958. The evolution of some traction epiphyses in birds and

312 mammals. Journal of Anatomy 92(4):593-601.

313 Benjamin M, \& Ralphs JR. 1997. Tendons and ligaments-an overview. Histology and

314 Histopathology 12(4):1135-1144.

315 Bezuidenhout AJ. 1999. Anatomy. In: Deeming DC, ed. The ostrich: biology, production and 316 health. CABI Publishing 13-50.

317 Carter DR. 1987. Mechanical loading history and skeletal biology. Journal of Biomechanics 318 20(11):1095-1109.

319 Carter DR, Mikić B, \& Padian K. 1998. Epigenetic mechanical factors in the evolution of long 320 bone epiphyses. Zoological Journal of the Linnean Society 123(2):163-178.

321 Cracraft J. 1971. The functional morphology of the hind limb of the domestic pigeon, Columba 322 livia. Bulletin of the AMNH 144:171-268.

323 De Vriese B. 1909. Recherches sur l'anatomie comparée de la rotule. Bulletin de L'Academie 324 Royale de Medecine de Belgique.

325 Fowler ME. 1991. Comparative clinical anatomy of ratites. Journal of Zoo and Wildlife Medicine 326 22(2):204-227.

327 Fuss FK. 1989. Anatomy of the cruciate ligaments and their function in extension and flexion of 328 the human knee joint. American Journal of Anatomy 184(2):165-176.

329 Fuss FK. 1991. Anatomy and function of the cruciate ligaments of the domestic pig (Sus scrofa 330 domestica): a comparison with human cruciates. Journal of Anatomy 178:11.

331 Fuss FK. 1996. Tibiofibular junction of the South African ostrich (Struthio camelus australis).

332 Journal of Morphology 227(2):213-226.

333 Fuss FK, \& Gasser CR. 1992. Cruciate ligaments of the avian knee: insight into a complex

334 system. Journal of Morphology 214(2):139-151.

335 Gangl D, Weissengruber GE, Egerbacher M, \& Forstenpointner G. 2004. Anatomical description

336 of the muscles of the pelvic limb in the ostrich (Struthio camelus). Anatomia, Histologia,

337 embryologia 33(2):100-114.

338 Giori NJ., Beaupre GS, \& Carter DR. 1993. Cellular shape and pressure may mediate 339 mechanical control of tissue composition in tendons. Journal of Orthopaedic Research 340 11(4):581-591.

341 Haines RW. 1942. The tetrapod knee joint. Journal of Anatomy 76(3):270-301. 
342 Haughton S. 1864. Notes on animal mechanics: No. 3. On the muscular mechanism of the leg of

343 the ostrich. Proceedings of the Royal Irish Academy 9:50-61.

344 Hutchinson JR. 2002. The evolution of hindlimb tendons and muscles on the line to crown-group

345 birds. Comparative Biochemistry and Physiology Part A: Molecular \& Integrative Physiology

346 133(4):1051-1086.

347 Hutchinson JR, Rankin JW, Rubenson J, Rosenbluth KH, Siston RA, Delp SL. (2014)

348 Musculoskeletal modelling of an ostrich (Struthio camelus) pelvic limb: Influence of limb

349 orientation on muscular capacity during locomotion. PeerJ PrePrints 2:e513v1

350 http://dx.doi.org/10.7287/peerj.preprints.513v1

351 Kim HT, Olson WM, \& Hall BK. 2009. Effects of hind limb denervation on the development of

352 appendicular ossicles in the dwarf African clawed frog, Hymenochirus boettgeri (Anura: Pipidae).

353 Acta Zoologica 90(4):352-358.

354 Macalister A. 1864. On the anatomy of the ostrich (Struthio camelus). Proceedings of the Royal

355 Irish Academy 9:1-24.

356 Mikic B, Johnson, TL, Chhabra AB, Schalet BJ, Wong M, \& Hunziker EB. 2000. Differential

357 effects of embryonic immobilization on the development of fibrocartilaginous skeletal elements.

358 Journal of Rehabilitation Research and Development 37(2):127-134.

359 Nowlan NC, Prendergast PJ, \& Murphy P. 2008. Identification of mechanosensitive genes during 360 embryonic bone formation. PLoS Computational Biology 4(12):e1000250.

361 Osborne AC, Lamb KJ, Lewthwaite JC, Dowthwaite GP, \& Pitsillides AA. 2002. Short-term rigid 362 and flaccid paralyses diminish growth of embryonic chick limbs and abrogate joint cavity 363 formation but differentially preserve pre-cavitated joints. Journal of Musculoskeletal and 364 Neuronal Interactions 2(5):448-456.

365 Parsons, FG. 1904. Observations on traction epiphyses. Journal of Anatomy and Physiology, 366 38(3):248-258.

367 Regnault S, Pitsillides AA, Hutchinson JR. 2014. Structure, ontogeny and evolution of the 368 patellar tendon in emus (Dromaius novaehollandiae) and other palaeognath birds. PeerJ 369 PrePrints 2:e404v1.

370 Rehder, U. 1983. Morphometrical studies on the symmetry of the human knee joint: femoral 371 condyles. Journal of Biomechanics 16(5);351-361.

372 Rewcastle, SC. 1983. Fundamental adaptations in the lacertilian hind limb: a partial analysis of

373 the sprawling limb posture and gait. Copeia 476-487.

374 Roddy KA, Kelly GM, Van Es MH, Murphy P, \& Prendergast PJ. 2011. Dynamic patterns of 375 mechanical stimulation co-localise with growth and cell proliferation during morphogenesis in the 376 avian embryonic knee joint. Journal of Biomechanics 44(1):143-149.

377 Rubenson J, Lloyd DG, Besier TF, Heliams DB, \& Fournier PA. 2007. Running in ostriches 378 (Struthio camelus): three-dimensional joint axes alignment and joint kinematics. Journal of 379 Experimental Biology 210(14):2548-2562. 
380 Rubenson J, Lloyd DG, Heliams DB, Besier TF, \& Fournier PA. 2010. Adaptations for

381 economical bipedal running: the effect of limb structure on three-dimensional joint mechanics.

382 Journal of The Royal Society Interface rsif20100466.

383 Sarin VK, \& Carter DR. 2000. Mechanobiology and joint conformity regulate endochondral

384 ossification of sesamoids. Journal of Orthopaedic Research 18(5):706-712.

385 Sarin VK, Erickson GM, Giori NJ, Bergman AG, \& Carter DR. 1999. Coincident development of

386 sesamoid bones and clues to their evolution. The Anatomical Record 257(5):174-180.

387 Scapinelli R, \& Little K. 1970. Observations on the mechanically induced differentiation of

388 cartilage from fibrous connective tissue. The Journal of Pathology 101(2):85-91.

389 Shufeldt RW. 1883. Remarks upon the osteology of Phalacrocorax bicristatus. Science 41:640390642.

391 Shufeldt RW. 1884. Concerning some forms assumed by the patella in birds. Proceedings of the 392 United States National Museum 7:324-331.

393 Smith NC, Wilson AM, Jespers KJ, \& Payne RC. 2006. Muscle architecture and functional

394 anatomy of the pelvic limb of the ostrich (Struthio camelus). Journal of Anatomy 209(6):765-779.

395 Stannius H. 1850. Nouveau manuel d'anatomie compare. Tome II: Animaux vertébrés. 286.

396 Vickaryous MK, \& Olson WM. 2007. Sesamoids and ossicles in the appendicular skeleton. Fins 397 into limbs: evolution, development, and transformation 323-341.

398 Vogel KG, \& Peters JA. 2005. Histochemistry defines a proteoglycan-rich layer in bovine flexor 399 tendon subjected to bending. J Musculoskelet Neuronal Interact 5(1):64-69.

400 Wagner M. 2004. Die osteologie der hinterextremität und des beckengürtels beim afrikanischen 401 strauss (Struthio camelus linné 1758). Doctor Medicinae Veteriniae Dissertation,

402 Veterinärmedizinische Universität Wien.

403 Walker ML. 1890. On the form of the quadrate bone in birds. In: Thompson DW, ed. Studies 404 from the Museum of Zoology in University College, Dundee

405 Zinoviev AV. 2006. Notes on the hind limb myology of the ostrich (Struthio camelus).

406 Ornithologia 33:53-62. 
1

Digital radiograph (A) and line drawing (B) of the ostrich right knee joint, in lateral view, showing sagittal plane locations of the two patellae with respect to bones and soft tissues.

A

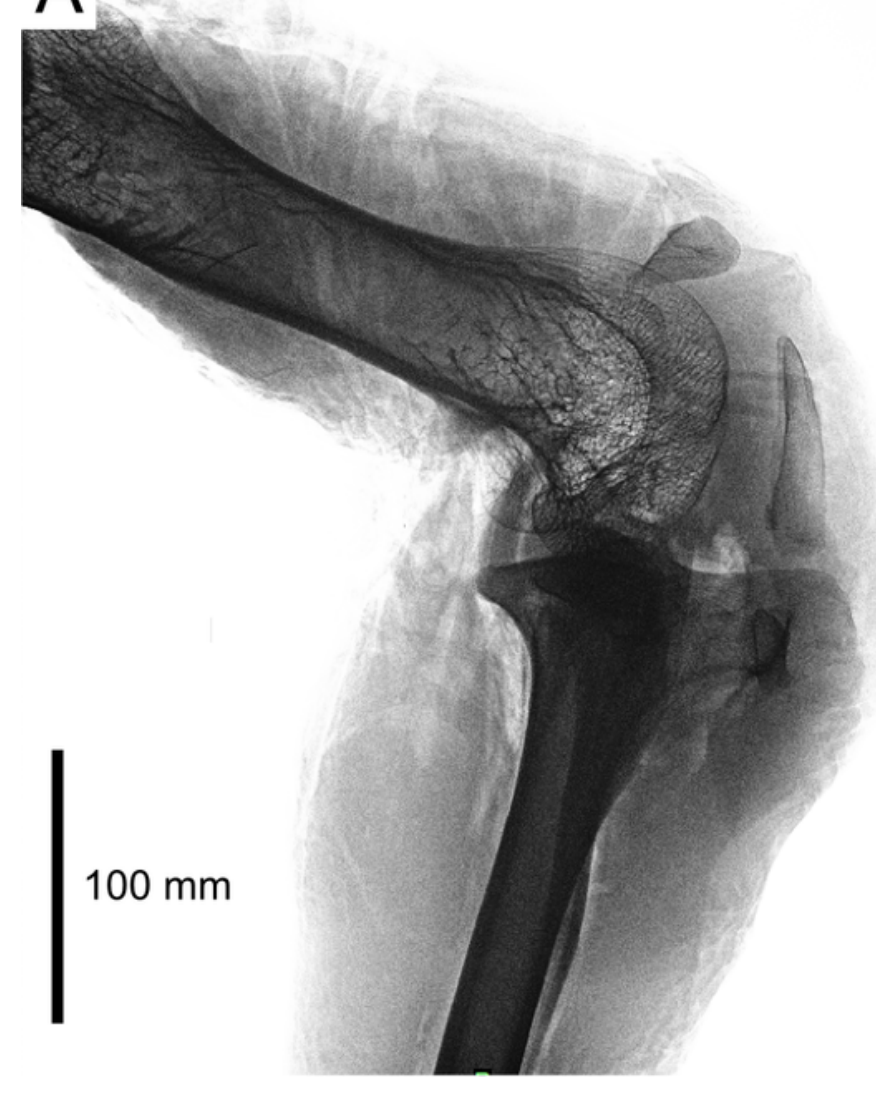

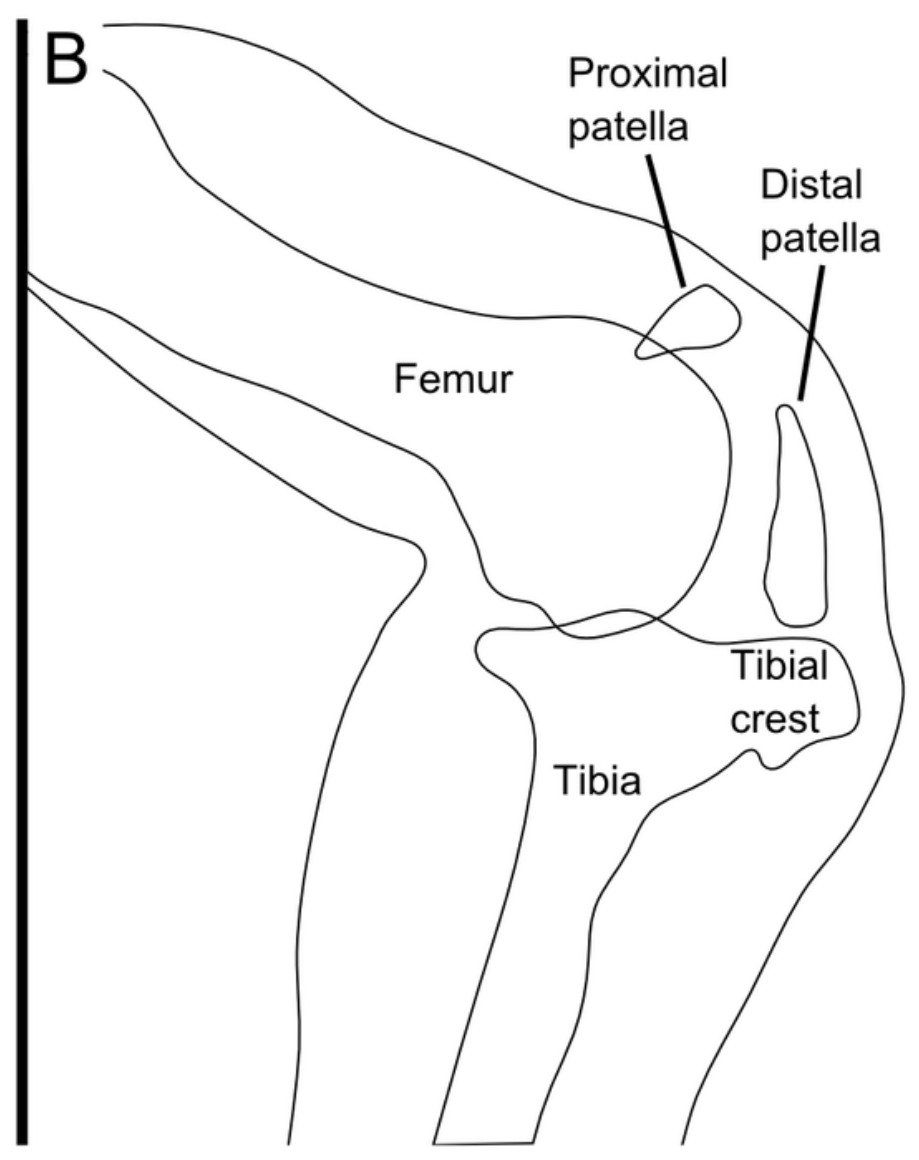




\section{Table $\mathbf{1}_{\text {(on next page) }}$}

The measured lengths of the distal patella and femur in dissected and museum specimens, as well as the ratio of the two.

Specimen RVC2 in italics is the main individual in this study. ${ }^{*}$ These specimen possess both femora and distal patellae; average lengths are shown. NHMUK specimen numbers pertain to osteological specimens held in The Natural History Museum, Tring, Hertfordshire, UK. RVC specimen numbers refer to specimens held at The Royal Veterinary College, Hatfield, Hertfordshire, UK. 


\section{PeerJ Reviewing Manuscript}

\begin{tabular}{|c|c|c|c|}
\hline Subject & $\begin{array}{l}\text { Distal } \\
\text { patella } \\
\text { length } \\
(\mathrm{mm})\end{array}$ & $\begin{array}{l}\text { Femur } \\
\text { length } \\
(\mathrm{mm})\end{array}$ & $\begin{array}{l}\text { Rati } \\
\text { o }\end{array}$ \\
\hline NHMUK & & & 0.14 \\
\hline $\begin{array}{l}\text { (1888.3.15.1) } \\
\text { NHMUK }\end{array}$ & 39.5 & 277.0 & $\begin{array}{r}3 \\
0.22\end{array}$ \\
\hline $\begin{array}{l}(1857.2 .24 .10)^{*} \\
\text { NHMUK }\end{array}$ & 64.9 & 292.5 & $\begin{array}{r}2 \\
0.18\end{array}$ \\
\hline $\begin{array}{l}(1895.10 .14 .1) \\
\text { NHMUK }\end{array}$ & 57.7 & 306.0 & $\begin{array}{r}9 \\
0.18\end{array}$ \\
\hline $\begin{array}{l}(1925.5 .12 .1) \\
\text { NHMUK }\end{array}$ & 57.7 & 312.0 & $\begin{array}{r}5 \\
0.18\end{array}$ \\
\hline $\begin{array}{l}(1915.3 .29 .1)^{*} \\
\text { NHMUK }\end{array}$ & 51.2 & 272.0 & $\begin{array}{r}8 \\
0.19\end{array}$ \\
\hline$(1894.3 .17 .1)^{*}$ & 62.5 & 314.0 & 9 \\
\hline NHMUK (1954.5.1)* & 61.7 & 292.5 & $\begin{array}{r}0.21 \\
1\end{array}$ \\
\hline NHMUK (1972.1.2) & 44.9 & 284.0 & $\begin{array}{r}0.15 \\
8\end{array}$ \\
\hline RVC1 & 33.1 & 306.0 & $\begin{array}{r}0.10 \\
8\end{array}$ \\
\hline RVC2 & 75.7 & 317.0 & $\begin{array}{r}0.23 \\
9\end{array}$ \\
\hline RVC3 & 67.2 & 307.2 & $\begin{array}{r}0.21 \\
9 \\
0.1\end{array}$ \\
\hline $\begin{array}{l}\text { Average } \\
\text { Standard } \\
\text { deviation }\end{array}$ & $\begin{array}{r}56.0 \\
8.4\end{array}$ & $\begin{array}{r}298.2 \\
14.8\end{array}$ & $\begin{array}{r}87 \\
0.0 \\
24\end{array}$ \\
\hline
\end{tabular}




\section{2}

Three-dimensional model of the ostrich right knee, showing bones, ligaments, and menisci.

LatCL $($ dark blue $)=$ lateral collateral ligament, MedCL $($ green $)=$ medial collateral ligament, CranCL (purple) $=$ cranial cruciate ligament, CaudCL (yellow) = caudal cruciate ligament, meniscus (cyan). A) Proximal view of ligaments, menisci, tibia, and fibula; B) Cranial view of femur, tibia, fibula, proximal patella, distal patella, ligaments, and menisci.

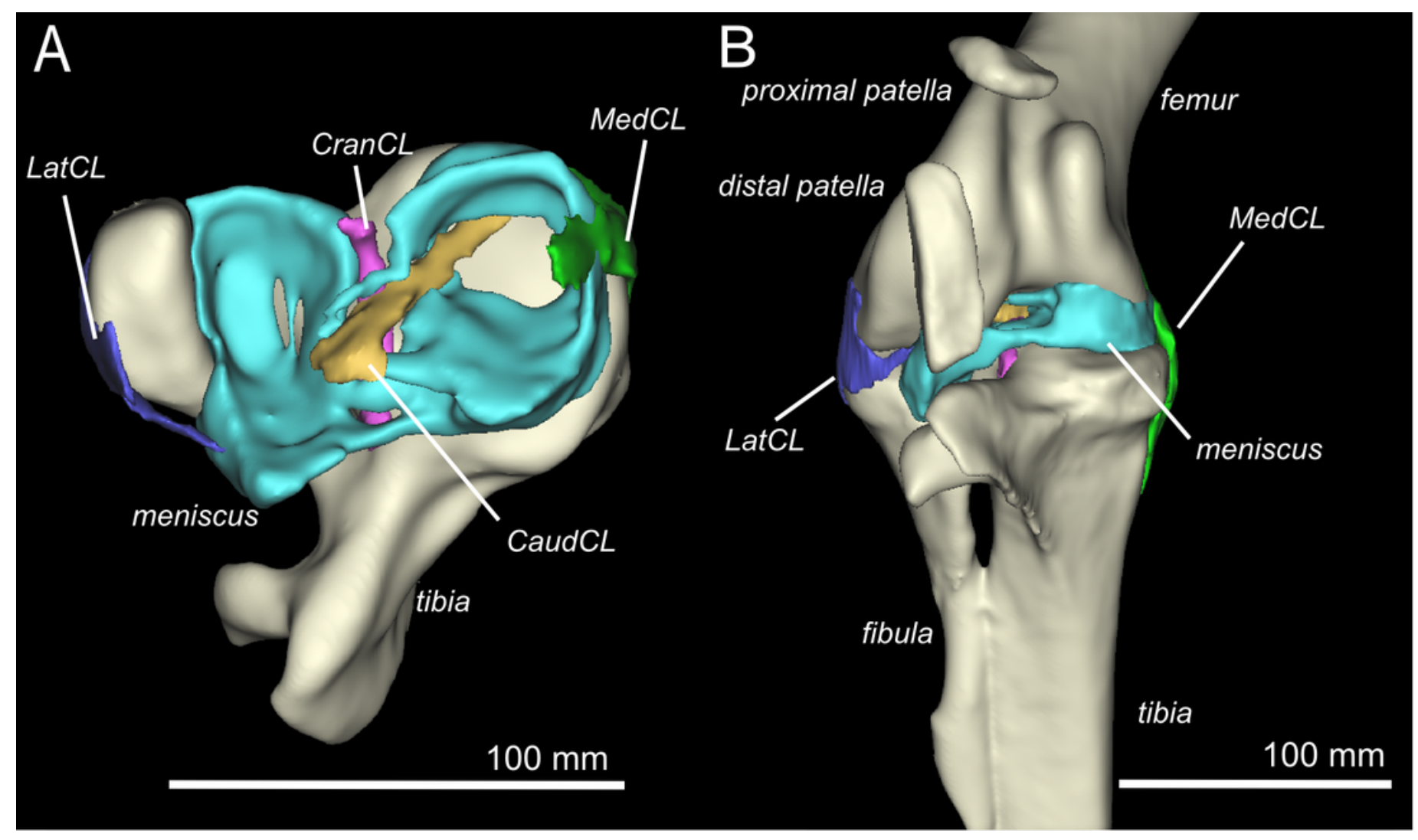




\section{3}

Cruciate ligament and meniscal insertion sites

A) Proximal view of the proximal right tibia and fibula, showing distal cruciate ligament and meniscal insertion sites B) cruciate (speckled) and meniscal (solid) attachment sites on the distal femur (left and right columns) and proximal tibia (central column). Attachment sites shown in Fuss (1992; top row) compared with what we observed (bottom row). Figure modelled after Fuss (1992).
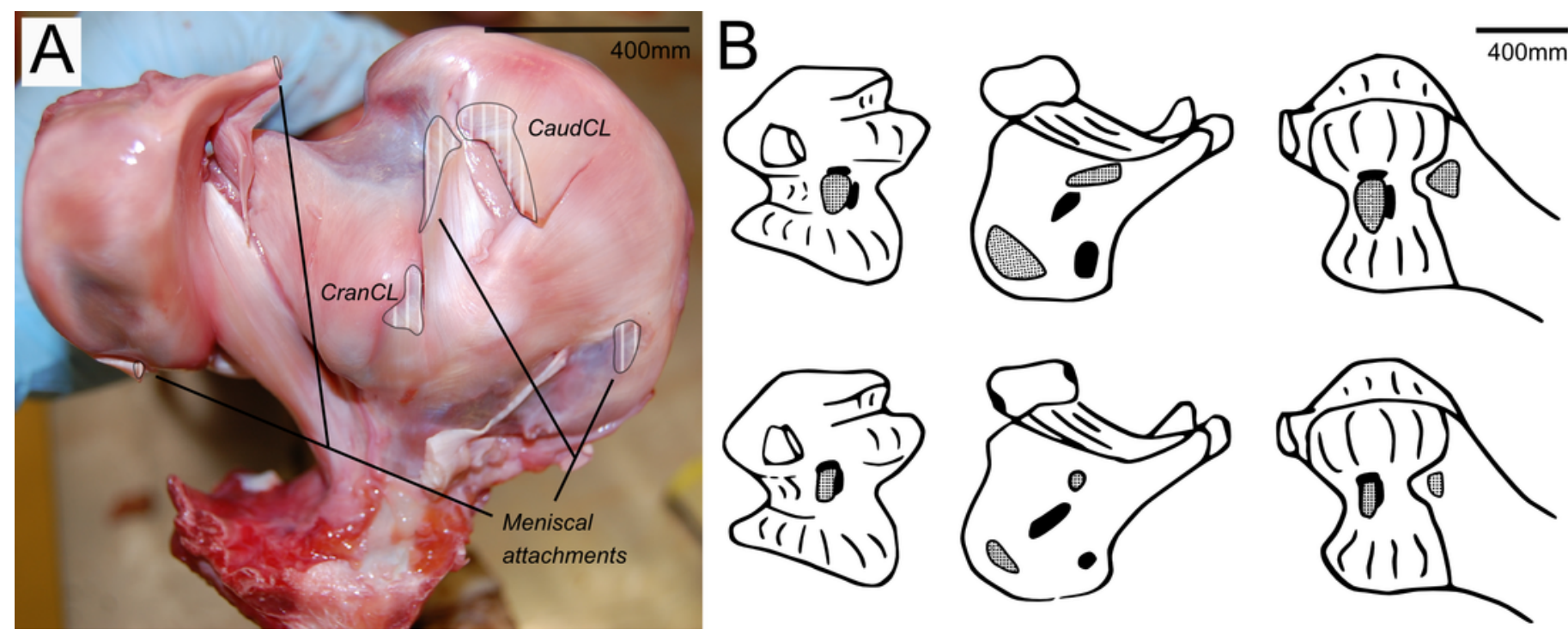
4

Representation of knee, in anterolateral view, showing superficial (A) and deep (B) muscles that attach to the tendofascial sheet containing the two patellae.

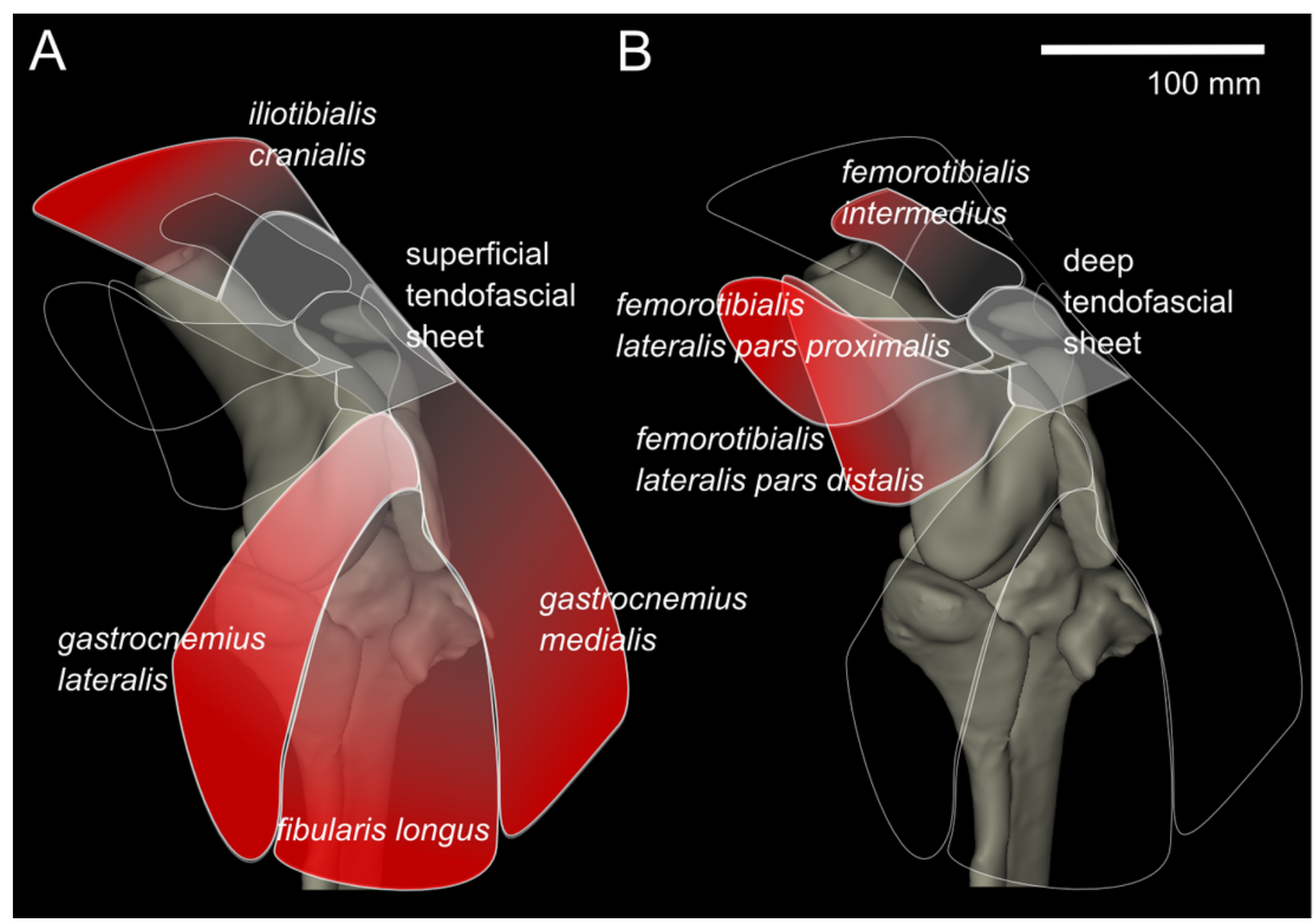

